\title{
Gender dysphoria in adolescence: current perspectives
}

This article was published in the following Dove Press journal:

Adolescent Health, Medicine and Therapeutics

\author{
Riittakerttu \\ Kaltiala-Heino ${ }^{1-3}$ \\ Hannah Bergman ${ }^{4}$ \\ Marja Työläjärvi ${ }^{2}$ \\ Louise Frisén ${ }^{4}$ \\ 'Faculty of Medicine and Life \\ Sciences, University of Tampere, \\ Tampere, Finland; ${ }^{2}$ Department of \\ Adolescent Psychiatry, Tampere \\ University Hospital, Tampere, \\ Finland; ${ }^{3}$ Vanha Vaasa Hospital, Vaasa, \\ Finland; ${ }^{4}$ Department of Clinical \\ Neuroscience, Karolinska Institutet, \\ Stockholm, Sweden
}

Correspondence: Riittakerttu Kaltiala-Heino

Tampere University Hospital, Box 2000, 3352I Tampere, Finland

Tel +358503392583

Email merihe@uta.fi

\begin{abstract}
Increasing numbers of adolescents are seeking treatment at gender identity services in Western countries. An increasingly accepted treatment model that includes puberty suppression with gonadotropin-releasing hormone analogs starting during the early stages of puberty, cross-sex hormonal treatment starting at $\sim 16$ years of age and possibly surgical treatments in legal adulthood, is often indicated for adolescents with childhood gender dysphoria (GD) that intensifies during puberty. However, virtually nothing is known regarding adolescent-onset GD, its progression and factors that influence the completion of the developmental tasks of adolescence among young people with GD and/or transgender identity. Consolidation of identity development is a central developmental goal of adolescence, but we still do not know enough about how gender identity and gender variance actually evolve. Treatment-seeking adolescents with GD present with considerable psychiatric comorbidity. There is little research on how GD and/ or transgender identity are associated with completion of developmental tasks of adolescence.
\end{abstract} Keywords: gender dysphoria, gender identity, adolescence, developmental tasks

\section{Gender dysphoria and related concepts}

The fifth edition of the Diagnostic and Statistical Manual of Mental Disorders (DSM-5) defines gender dysphoria (GD) as a condition in which a person has marked incongruence between the expressed or experienced gender and the biological sex at birth. This causes clinically significant distress or impairment in social, occupational or other important areas of functioning. Individuals with GD experience a strong desire to be treated as the other gender (or some alternative gender different from their assigned gender) and/or to be rid of their sex characteristics, and/or the strong conviction of having feelings and reactions typical of the other gender (or some alternative gender). The previous diagnostic term, gender identity disorder, was rejected in the DSM-5 to avoid pathologizing identity.

According to the International Classification of Diseases (ICD)- $10,{ }^{2}$ transsexualism is defined as a desire to live and be accepted as a member of the opposite sex, usually accompanied by a sense of discomfort with or the inappropriateness of one's anatomical sex and a wish to undergo surgery and hormonal treatment to make the body as congruent as possible with the individual's preferred sex. The forthcoming ICD-11 will reconceptualize gender identity-related diagnoses using gender incongruence as the main term. ${ }^{3}$

In addition to the DSM-5 diagnostic term, gender dysphoria can also refer to anxiety and distress about gender features at large. Gender nonconformity refers to 
behaviors and an appearance that are considered atypical of an individual's assigned gender. Gender variance refers to a spectrum of gender experience, in contrast to the dichotomized conception of gender. The term "transgender" is used as an umbrella term to refer to wider variation of gender identities. Not all who identify as transgender or display gender nonconformity or gender variance suffer from dysphoria.

In this article, we use the DSM-5 and ICD-10 terms "gender dysphoria (GD)" and "transsexualism/transsexual", respectively, when referring to diagnosed clinical samples, and also when referring to the literature published when earlier versions of the DSM classification were in use. We use "transgender" to refer to self-identified population samples and "gender dysphoria" to refer to those who present clinical symptoms.

\section{How common are GD and transgender identity among adults and adolescents?}

The number of people who seek treatment suggest that maleto-female transsexualism has a prevalence of 6.8/100,000 and female-to-male transsexualism has a prevalence of 2.6/100,000 among adults. ${ }^{4,5}$ In the Netherlands, $0.6 \%$ of men and $0.2 \%$ of women (aged 15-70 years) reported incongruent gender identity and a desire to undergo sex reassignment (SR). ${ }^{6}$ Population surveys have suggested that about $0.5 \%$ of adults in the general population identify as transgender. ${ }^{5,7}$

The number of adolescents contacting specialized gender identity services has risen considerably over the past decade across Europe and North America. ${ }^{8,9}$ No conclusions regarding the prevalence of GD in general or of GD/transsexualism specifically can be drawn based on these increases. Studies using short (one to three item) self-reports of gender identity and its variance suggest that $0.17 \%-1.3 \%$ of adolescents and young adults identify as transgender., ${ }^{5,10}$ A school-based survey eliciting gender experiences with scales commonly used at gender identity services suggested that $1.3 \%$ of $16-19$ year olds had potentially clinically significant gender dysphoria. ${ }^{11}$

\section{Gender identity}

Identity is the way one understands, describes and expresses oneself and the reflection of those entities to others. Identity consists of many integrated aspects such as gender, nationality, language, academic and occupational endeavors, and religious and political convictions. It is affected by interpersonal relationships, society and different events throughout the life course. ${ }^{12}$ Adolescence is an important period of identity formation and integration. ${ }^{12,13}$ Adolescents and young adults establish their identity by actively exploring identity-related choices and making identity commitments in their chosen directions. $^{12,13}$

Gender identity concerns the individual's core sense of being "female", "male" or another gender. The development of gender identity is a complex process affected by multiple factors. ${ }^{14,15}$ In the research tradition of gender identity, the broad focus has been on the theme "sex differences", and two major topics have received the most attention: the description and measurement of sex differences and the etiology of these differences. ${ }^{16}$ Several theories have been proposed. According to early psychodynamic theories, gender variant behavior was hypothesized to derive from parent-infant interpersonal issues or trauma (see Gray et $\mathrm{al}^{15}$ ). However, these theories have not undergone adequate scientific testing. Gender identity development has mostly been described from the viewpoint of cognitive and social learning theories, which argue that human beings are active constructors of cognitive schemas, including gender, in continuous interaction with the environment. ${ }^{14}$ Other theories on processes of gender typing have focused on proximal and distal biological influences, genetic and epigenetic or hormonal and neural mechanisms as well as brain anatomy differences in the etiology of gendered behavior and gender variance. ${ }^{17-19}$ There are structural and functional sex differences in the brain, some of them observable across the life span and others only during specific developmental phases. Sex differences in the brain are largely determined by steroid hormone exposure during a perinatal sensitive period that alters subsequent hormonal and non-hormonal responses throughout the lifespan, but they also depend on genes on sex chromosomes. Moreover, there is continuous interaction between genes and experiences, "epigenetics", which changes the expression of genes without any change in the underlying DNA sequence. Research suggests that, for example, early social experiences may act as such epigenetic influence that they ultimately shape lasting sex differences in brain and behavior, ${ }^{20-22}$ but a lot more research is needed in this field to obtain solid knowledge relevant for understanding GD.

While the theories proposed in the past have generally been either essentialist or social cognitive/constructivist in nature, researchers today are expanding the focus to include the bio-psycho-social processes that probably occur across development. ${ }^{14,15,23}$

\section{Childhood GD and puberty development}

GD in childhood (GDC) ${ }^{1}$ describes a feeling of incongruence between the experienced (psychological) gender and the sex 
assigned at birth. A corresponding diagnosis is included in the ICD-10. ${ }^{2}$ Healthy children vary considerably in their gendered behaviors. ${ }^{15}$ The diagnosis of GD in prepubescent children has been widely discussed throughout the history of gender identity research, mainly in terms of weighing the risk of stigmatization against diagnosis as a means of access to publicly funded or insurance-covered health care. ${ }^{3,24}$ The prevalence of GDC is not known. ${ }^{5}$

Adolescence is a crucial time for identity and psychosexual development in young people with gender identity concerns. ${ }^{25}$ The outcomes of GDC have been discussed in terms of its persistence and desistence. For most children with GDC, whether GD will persist or desist will probably be determined between the ages of 10 and 13 years, ${ }^{26}$ although some may need more time. ${ }^{27}$ Evidence from the 10 available prospective follow-up studies from childhood to adolescence (reviewed in the study by Ristori and Steensma ${ }^{28}$ ) indicates that for $\sim 80 \%$ of children who meet the criteria for GDC, the GD recedes with puberty. Instead, many of these adolescents will identify as non-heterosexual. ${ }^{17,29}$ Steensma et $\mathrm{al}^{26}$ interviewed adolescents with different outcomes of GDC (persistence or desistance). The adolescents mentioned social environment, the anticipated results of bodily changes and first romantic and/or sexual experiences as central factors in the desistance or persistence of GD.

\section{Treatment of GD intensifying in puberty: the Dutch model}

The most commonly used guidelines for the treatment of GD in children and adolescents are those of The Endocrine Society $^{30}$ and the Standard of Care from the World Professional Association for Transgender Health, ${ }^{31}$ which are based on the so-called Dutch Model protocols published and practiced at the Amsterdam Gender Clinic in the Netherlands. ${ }^{32}$

The Dutch protocol recommends medical treatment if GD intensifies in puberty, while the care for children with GD and their families consists of providing information, psychological support, parental or/and family counseling. In adolescents, medical treatment is recommended at age 12 years and older for those who are in or beyond the early stages (Tanner II-III) of puberty and are still experiencing persistent GD. Puberty suppression with gonadotropinreleasing hormone analogs is part of the protocol for these patients. The purpose of puberty suppression is to relieve the psychological suffering caused by the development of secondary sex characteristics, to give the adolescent time to make a balanced decision regarding whether to undergo actual medical gender-confirming treatment (with cross-sex hormones and surgery) and to make social "passing" in the experienced gender easier. Cross-sex hormones are used for adolescents aged 16 years and older who continue to experience persistent GD. People aged 18 years and older with a diagnosis of GD may undergo SR surgery. ${ }^{32}$

\section{Outcome of and ethical debates around medical interventions for GD in adolescence}

The Dutch protocol is largely used, but it has its critics. ${ }^{33-35}$ Controversy regarding the use of drugs for puberty touches on fundamental ethical concepts in pediatrics: the best interests of the minor, autonomy and the role of social context. Professionals recognize the distress of young people with GD and feel an urge to treat them. At the same time, most of these professionals have doubts because of the lack of data regarding long-term physical and psychological outcomes. ${ }^{36,37}$

Reports of the outcomes of puberty suppression treatment in adolescents have shown reasonable safety and good outcomes regarding patient satisfaction and psychosocial functioning, but research is still scarce. Nevertheless, puberty suppression is not indicated in a considerable proportion of gender dysphoric minors because of several reasons, for example, severe psychiatric comorbidity, considerable instability of psychosocial support or onset of GD later during puberty and diagnostic uncertainty; ${ }^{38-40}$ nevertheless, more follow-up data even from patients who are fulfilling the criteria for "the Dutch model" are still needed. ${ }^{37}$

\section{Psychiatric disorders among adolescents with GD}

Descriptive studies of adolescents referred to specialized gender identity services at different centers in Europe and North America have mainly suggested that $\sim 40 \%-45 \%$ of these young people present with clinically significant psychopathology. ${ }^{38,39,41-50}$ The lowest figures for psychiatric comorbidity (one-third of the presenting population) were reported in the Netherlands, ${ }^{41}$ and the highest (up to three quarters) was reported in Finland and Canada. ${ }^{39,50}$ Gender-referred adolescents actually appear to display clinically significant psychopathology to the same extent as adolescents referred to mental health services due to other reasons ${ }^{48,50}$ The most commonly reported disorders are depression and anxiety disorders. Self-harm and suicidal ideation/behavior are also common, whereas conduct disorder and antisocial development do not appear central in this population. 
Likewise, community-level information suggests that transgender-identifying youth present four to six times more often with depression and three to four times more often with self-harm and/or suicidal behavior compared with cisgender adolescents. ${ }^{10,51}$ Clinical and population data, though scarce, also suggest an overrepresentation of eating pathology among adolescents with GD or transgender identity. ${ }^{46,52}$

An increased prevalence of autism spectrum disorders (ASDs), varying from $\sim 6 \%$ to over $20 \%$, has been reported among samples of adolescents referred to gender identity services. ${ }^{39,42,46,53}$ This vastly exceeds the estimated prevalence of $0.6 \%-0.7 \% \%^{54}$ in the general population. In comparison, among children and early adolescents with ASDs, gender variance is $>7$-fold more common than among non-referred controls. $^{53,55}$

Hypotheses to explain this are manifold. The theory of the extreme male brain suggests that individuals with ASD demonstrate an extreme of the typical male pattern of behaviors and cognitions originating from high levels of fetal testosterone. High fetal levels could likewise contribute to GD in natal girls, explaining their male identity and behavior. However, this theory cannot explain the association between ASD and GD in natal boys. Social factors-related hypotheses propose that the social perception and communication difficulties typical of autism could make a child more likely to miss social cues regarding how to conform to gender norms or to identify with the opposite sex when he/she faces difficulties joining the peer group of her/his own sex. Hypotheses focusing on individual psychological characteristics suggest, firstly, that gender could be among the preoccupations or obsessions often seen in ASDs. On the other hand, the development of atypical gender identity in autism could relate to the developmental rigidity typical of autism. Individuals with ASD might not reach normative flexibility in gender development necessary to deal with gender variant feelings, which might lead to the overrepresentation of ASD in GD. ${ }^{53,56}$ The suggested causes, however, remain speculative. In a recent study, both boys and girls with GD displayed elevated levels of autistic symptomatology in all subdomains of autism, which did not exclusively support any of the suggested hypotheses. ${ }^{56}$ Nevertheless, ASDs pose particular challenges for the diagnosis and treatment of GD in adolescents.

\section{GD and the developmental tasks of adolescence}

"Developmental tasks" refer to the normative developmental milestones that should be reached during a given developmental stage..$^{57,58}$ They arise from interactions among physical development, personal attributes and societal expectations. Favorable completion of the developmental tasks of a given stage is a prerequisite for success in the subsequent stages. The developmental tasks of adolescence were first formulated by Havighurst ${ }^{57}$ and comprise accepting one's body, adopting a masculine or feminine social role, achieving emotional independence from parents, developing close relationships with peers of the same and opposite genders, preparing for an occupation, preparing for marriage and family life, establishing a personal value or an ethical system and achieving socially responsible behavior. Although puberty now occurs earlier and the transition to adulthood occurs later than they did when these developmental tasks were initially proposed, they remain relevant. ${ }^{58}$ The relationship with one's own body and the acquisition of a gendered social role - not necessarily binary - are by definition challenging for adolescents with GD. In the following sections, we discuss the available information on GD/transgender identity and the other developmental tasks of adolescence.

\section{GD in adolescence and relationships with parents}

Parents of adolescents with GD and/or transgender identity may face special challenges that are shaped by a variety of factors, such as ethnicity, religious background, social class and the prevailing attitudes in their community and society. ${ }^{59,60}$ These challenges likely shape the support that a nonconforming adolescent can receive. Adverse parental reactions toward an adolescent's gender nonconformity have been noted as a special risk, ${ }^{61}$ but parents of sexual- and gender-minority offspring have also reported particular positive aspects of being a parent in this situation, such as personal growth, unconditional love, activism, social connection and closer relationships ${ }^{62}$ However, few studies have empirically explored the parental reactions and support among youth with GD and/or transgender identity.

In a Canadian community study of transgender-identifying youth, ${ }^{63}$ of those who had disclosed their gender identity to their parents, $34 \%$ considered their parents "very" supportive and $25 \%$ considered their parents "somewhat" supportive. Forty-two percent reported that their parents were "not very" or "not at all" supportive. However, the study was based on a nonrandom sample and solely adolescent self-reports, so findings need to be interpreted with caution and causalities cannot be concluded. Strong perceived parental support was, nevertheless, associated with many positive mental health outcomes. Lack of parental support was associated 
with inadequate housing and homelessness in addition to negative psychological outcomes. Better parental support has also been associated with fewer risk-taking sexual behaviors among transgender youth. ${ }^{64}$

In a community study of trans female adolescents and young adults, ${ }^{65}$ more than half of the participants reported that their parents supported their gender identity, showed their support in many ways and believed the respondent could have a happy future as a trans adult. However, approximately two in five respondents had not experienced parental acceptance. Parental acceptance was associated with perceiving parents as the primary source of social support.

In a school-based survey ${ }^{51}$ transgender-identifying adolescents felt less often (odds Ratio 0.3) than their cis-gender peers that at least one parent cared for them.

Studies of clinically referred gender dysphoric youth have rarely addressed parent-related issues. Simons et al ${ }^{66}$ reported that in a clinical sample of adolescents with GD, parental support was significantly associated with higher life satisfaction, lower perceived burden of being transgender and fewer depressive symptoms. In a Finnish study comparing childhood gender identity in community and clinical samples, a smaller proportion of adolescents with GD than of non-referred adolescents in the population agreed with the statement "I always felt that my parents cared fore me." ${ }^{11}$ It was also noticed that the clinically referred adolescents with GD less commonly lived with both their parents than the adolescents in the normal population (48\% vs. $78 \%$ ). ${ }^{67}$ In British and Spanish samples of gender-referred adolescents, parental divorce was observed in the background of approximately three in five participants, but the authors did not compare this finding with a corresponding rate in the general population. ${ }^{46,49}$

\section{Gender nonconformance and peer relationships in adolescence}

During adolescence, peer relationships are critical for psychological well-being. ${ }^{68,69}$ Peer relationships also shape development, including aspects of gender identity consolidation. ${ }^{70}$ Loneliness and social isolation from peer relationships is associated with developmental difficulties and impaired mental health. ${ }^{71,72}$ An important peer network-related risk factor is bullying. ${ }^{73}$

Observations in referred samples of adolescents with GD suggest considerable peer relationship difficulties. In both the $\mathrm{UK}^{46}$ and in Finland, ${ }^{39}$ approximately half of adolescents who presented at a specialized gender identity service reported significant experiences of being bullied. In the Finland study, $45 \%$ of the referred adolescents also had a history of marked periods of social isolation in childhood and/or adolescence. In the Netherlands and in Canada, self-, parent and teacher ratings indicated poorer peer relationships among adolescents referred for GD than in the same-aged population ${ }^{47,48}$ and poor peer relationships were an important correlate of mental health problems in this group. Similarly, in another Canadian comparison among gender-referred, mental health-referred and general population adolescents bullying was reported by the GD group more commonly than by population controls, and to the same extent as by those referred due to mental health issues. Gender-related bullying was most common among the GD group. ${ }^{74}$

On the population level, Clark et $\mathrm{al}^{51}$ found that transgender-identifying adolescents had 4.5-fold increased odds of being bullied and were approximately twice as likely to report being afraid for their personal safety, having been in a serious physical fight and having been hit or otherwise harmed by others, compared with their cisgender-identifying peers. They also less commonly felt that their friends cared about them and that school was okay.

Gender-nonconforming behavior is characteristic of both sexual- and gender-minority youth and has been associated with an increased likelihood of experiencing bullying and harassment in peer groups. ${ }^{75,76}$ Adolescents with GD likely represent the extreme end of gender nonconformity, and this may strongly contribute to their experiences of being bullied. Bullying and stigmatization have also been suggested to (partially) mediate the association between gender nonconformity and lower mental well-being across adolescence. . $^{747-79}$

However, not all the difficulties the gender dysphoric adolescents face in peer relationships can be explained by gender expression-related victimization or discrimination. In the Finnish clinical sample, of the gender identity-referred adolescents who had experienced severe bullying at school, three quarters had been bullied before they ever questioned their gender. Likewise, three-quarters of them reported that the bullying had not been related to gender expression or sexual identity, but to other factors such as not being slim, being successful at school or having unfashionable hobbies and interests. ${ }^{39}$ Bullying is a severe problem regardless of the reported reasons for it, but it is important to acknowledge that adolescents who develop GD also have unrelated difficulties that may need attention.

\section{GD, transgender identity and sexuality in adolescence}

Sexual orientation and gender identity are different entities, and transgender people present with a variety of sexual orientations. Nevertheless, sexual orientation has long been used 
to subtype GD/transsexualism. ${ }^{80}$ During adolescence, the different facets of sexual orientation - attraction, behavior and identity - may still be developing. It may be more important to determine whether adolescents with GD or transgender identity display developmentally appropriate and favorable involvement in romantic and erotic relationships.

In adolescence, sexual development accelerates. Young people's experiences of a maturing and changing body, sexuality and their developing gender identity affect intrapersonal, interpersonal and societal interactions. ${ }^{81}$ In Western countries, between one-tenth and one-third of adolescents first experience sexual intercourse by the age of 15 , and the vast majority experience it by age $20 .{ }^{82,83}$ Various practices of kissing and petting typically precede first sexual intercourse by several years. Early sexual activity has been viewed as a problem behavior associated with risky sexual behaviors, psychosocial difficulties and emotional and behavioral disorders. ${ }^{82,83}$ In contrast, in the late stages of adolescent development, a lack of experiences might suggest developmental difficulties.

GD and/or transgender identification could be expected to be associated with delayed sexual development, given that it is the sexual body, in particular, that is the source of distress in GD and that differing from the mainstream may increase the adolescent's risk of problems in social relationships, including dating, and sexual encounters. Sexual- and genderminority adolescents may also have a reduced availability of potential partners and increased challenges in finding potential partners than their heterosexual peers. ${ }^{84}$ However, developmental challenges have also been associated with premature and risky sexual behavior. ${ }^{82,85}$ Adolescents with GD and/or transgender identification could engage in risky sexual behaviors due to identity experiments or because associated mental health problems could increase their search for comfort in intimacy or decrease their self-protection skills.

To the best of our knowledge, the only study focusing on the sexual experiences of treatment-seeking adolescents with GD is that of Bungener et $\mathrm{al}^{86}$ from the Netherlands. They compared the sexual experiences of 137 transsexual adolescents (mean [SD] age 14.69 [2.2] years) with those of a same-aged adolescent population. Transsexual adolescents had fewer sexual experiences than the same-aged population in all areas measured (falling in love, romantic relationships, kissing, petting, intercourse). However, a majority of the transsexual adolescents had fallen in love and approximately half had been involved in romantic relationships. One quarter had experienced petting while undressed, and 5\% had experienced sexual intercourse. Fewer transsexual adolescents than the adolescents in the same-aged population ( $24 \%$ vs. $48 \%$ ) valued sex as important. In a descriptive study of clinically presenting adolescents with GD in the USA, ${ }^{45}$ nearly half of the respondents (mean [SD] age 19.2 [2.9] years) reported being sexually active.

Some population studies provide information regarding transgender identity in adolescence and aspects of sexual development. Korchmaros et $\mathrm{al}^{84}$ compared the romantic relationships of lesbian, gay, bisexual, transgender and questioning (LGBTQ) adolescents and those of adolescents with mainstream sexual and gender identities. Contrary to expectations, the LGBTQ adolescents were more experienced with romantic relationships and more active in initiating relationships both online and offline. Results were not reported separately for the transgender group. Robinson and Espelage $^{87}$ reported that LGBTQ adolescents were more likely to display risky sexual behaviors than same-aged non-LGBTQ youth. However, in more detailed analyses, the risk was associated with homosexual/bisexual orientation and not with transgender identity. Veale et $\mathrm{al}^{88}$ set out to study pregnancy involvement among transgender youth and the health correlates of this involvement. In a large $(n=923)$ sample of transgender-identifying youth, 540 responded to the pregnancy involvement item. Almost $5 \%$ of Canadian transgender adolescents had ever been pregnant or impregnated a partner; approximately the same proportion as their same-aged peers. Those with a history of pregnancy involvement were also more likely to have a history of sexually transmitted disease, but they did not differ from the rest of the transgender youth in terms of hormone use, living in the felt gender, self-reported mental health and level of social support.

Sexual harassment is a common problem among adolescent populations. ${ }^{89}$ Transgender-identifying adolescents appear to be at the greatest risk of sexual harassment and to experience the greatest distress due to it. ${ }^{89}$ Sexual harassment is suggested to function to maintain heteronormativity, which transgender adolescents likely challenge. Their perception of sexual harassment as more distressing compared with other adolescents could be due to harsher harassment, increased vulnerability due to uncertainty about self, or fear. ${ }^{89}$

Similarly, in a large school-based survey study on teen dating violence, ${ }^{90}$ the few transgender-identifying youth in the sample reported the highest victimization rates for physical dating violence, psychological dating abuse, cyber dating abuse and sexual coercion. Differences from cisgender adolescents varied from 2- to 7-fold for the different forms of violence. However, the transgender-identifying youth also reported the highest rates of perpetrating dating violence. Minority stress theory ${ }^{91}$ posits that the chronic stressors that 
minorities experience (e.g., gender-based discrimination) shape their coping mechanisms (such as substance use, aggression) and lead to adverse psychosocial and health outcomes. The particular vulnerability to perpetrating dating violence observed among transgender adolescents by Dank et $\mathrm{al}^{90}$ could be understood through minority stress theory, but more research is needed.

Transgender adolescents and young adults, particularly trans females, are at a disproportionately high risk of contracting human immunodeficiency virus and other sexually transmitted diseases. ${ }^{79,92}$ The risk of unprotected sex in this population has been associated with sex work and drug use, which are further associated with rejection, stigma and discrimination. ${ }^{79,92}$ Of the studies of referred samples, only one addressed sex work. ${ }^{45}$ In that sample, $6 \%$ of the referred adolescents reported engaging in the trading of sex.

Sexual education is an important way to promote positive and responsible sexual behaviors in youth. The planned curricula and practical applications likely vary widely across countries and schools. Sexual- and gender-minority youth were found to desire minority-inclusive sexual education in a study by Gowen and Wingez-Yanez. ${ }^{93}$ The sexual- and gender-minority youth felt that the sexual education that was offered isolated them by silencing them, adopting a heterocentric perspective and pathologizing minorities. Reflecting on the available sexual education in light of these findings is appropriate for all educators.

\section{Preparing for occupation: academic performance and socioeconomic status}

To the best of our knowledge, research has not specifically focused on academic performance and the progression to work life among adolescents with GD, but given the burden of psychiatric comorbidities among gender-referred youth, special needs regarding education are likely to exist.

Aspects of social relationships are relevant to well-being in school, school performance and pathways to occupation. Transgender youth have been reported to experience bullying and discrimination in schools, not only by peers but even by teachers; consequently, they perceive schools as unsafe places, which again increases the risk of non-attendance and poorer results. ${ }^{75,94}$ Gender- and sexuality-related victimization may impair academic performance through, for example, decreased motivation, concentration and self-efficacy and the resulting school avoidance and harmful coping strategies. ${ }^{94,95}$ Nevertheless, being "out" at school improves self-esteem among gender- and sexual-minority youth and increases their well-being, which can have a positive impact on academic performance. $^{94}$

School dropout is strongly linked to social exclusion. School dropout was associated with high masculinity in girls and low masculinity combined with high femininity in boys in a study of late-adolescent school dropouts and attenders in the Netherlands. ${ }^{96}$ The authors suggested that such deviation from gender norms increases the risk of unpopularity among peers, which again predisposes individuals toward school dropout. However, school dropout was also associated with very masculine attitudes and self-evaluations among boys. The role of gendered behaviors, attitudes and experiences in school adjustment and academic performance deserves further research.

In Clark et al's ${ }^{51}$ school-based survey, adolescents reporting non-cisgender identity came disproportionately often from families with high socioeconomic deprivation and less often felt that their family got along. Any explanation for this remains unknown; however, young people are likely to stay in the same socioeconomic position as their parents. ${ }^{97}$ Jacob and $\mathrm{Cox}^{98}$ also pinpointed transgender people's greater risk of having a disadvantaged socioeconomic status (in the USA), associating this with increased unemployment, and employment in low-paid jobs, because of stigmatization.

\section{Why the increase in referrals?}

Zucker et $\mathrm{al}^{99}$ observed an increase in the number of adolescents presenting at gender identity services in the early 2000s. Since then, several gender identity services for minors from across Western countries have reported increases. , $^{8,42,49}$ Simultaneously, the earlier overrepresentation of natal boys has equaled or turned to overrepresentation of natal girls. ${ }^{9}$ Natal girls now comprise from half ${ }^{49}$ to $\sim 90 \%{ }^{39}$ of clinical adolescent samples. The reasons for these changes are not known. The increase in referrals could be attributable to enhanced provision of services, or the threshold for seeking help may now be lower due to increased knowledge and improved societal acceptance. Aitken et al, ${ }^{9}$ however, did not find evidence supporting a lowered threshold to gender identity services. Sociocultural features related to what kind of identities are available for whom, and sex-related differences of pressure to conform may play a role.

\section{Comments}

Research regarding the clinical treatment of adolescents with GD has mainly focused on childhood-onset GD that intensifies during puberty, and the Dutch treatment protocol is also tailored for this group. There is little empirical knowledge 
regarding young people who experience their first signs of GD in adolescence, well after the onset of puberty, especially regarding biological girls. ${ }^{50,100}$ Among a treatment-seeking sample in the UK, 18\% experienced their first feelings of GD in adolescence ${ }^{46}$ compared with approximately two-thirds of the Finnish sample, ${ }^{39}$ and for the majority of adolescent-onset cases, GD presented in the context of severe mental disorders and general identity confusion. In such situations, appropriate treatment for psychiatric comorbidities may be warranted before conclusions regarding gender identity can be drawn. Gender-referred adolescents actually display psychopathology to the same extent as mental health-referred youth. ${ }^{48,50}$ In a nationwide long-term follow-up study of adult cases, psychiatric morbidity, suicide attempts and suicide mortality persisted as elevated after juridical and medical SR. ${ }^{101}$

Emerging discussions raise concern for post-pubertally abruptly emerging cross-gender identification ("rapid onset"), particularly among biological girls, suggesting a role for intensive media influences and generous group validation as shaping the understanding of, and giving new meanings to, the body discomfort common among female adolescents at large. ${ }^{100}$ The persistence of increasing adolescent-onset transgender identification is not known. ${ }^{5,100}$

More empirical research is needed regarding virtually all aspects of GD in adolescence to create treatment approaches that optimize these young people's future psychosocial health and well-being. It seems unlikely that all the psychopathology observed in the referred samples is secondary to gender identity issues and would resolve with hormonal and later surgical treatments. There is still no clear consensus regarding hormonal treatment for adolescents because long-term data are unavailable; ${ }^{36}$ actually, only one long-term follow up has been carried out, with a highly selected intervention group and an at baseline non-comparable comparison group. ${ }^{102}$

An affirmative approach ${ }^{103}$ is increasingly implemented in the health care of gender nonconforming children. This includes, based on a comprehensive psychological and psychosocial assessment, work with the children and their families and schools to support the gender-nonconforming minors to express themselves in a way that feels most comfortable for them. With the starting point that gender presentations are fluid and changing over time, gender variant children need to be allowed to freely explore a range of gender identities and expressions. A debate concerns whether or not a prepubertal child should be allowed to completely transition to live in other than birth gender. Concerns include that childhood transition may be forcing adolescents to proceed to biomedical interventions, as stepping back may be psychologically troublesome, even though identity development has taken a new direction. ${ }^{28,104}$

The etiology of gender incongruence remains unknown. Gender identity differentiation does not occur in a psychosocial vacuum; instead, research in the field suggests that the developmental course is influenced by numerous psychosocial factors, likely in continuous interaction with biological factors. ${ }^{23,105}$ Gray et $\mathrm{al}^{15}$ noted that the general narrative in the research literature concerning gender variation among children focuses on gender "atypical" behavior and deviation from "normative patterns", thus viewing gender in a binary way instead of as a wider spectrum of (healthy) identities, personalities and behaviors among children. This is surely relevant for adolescents as well. These authors also requested a shift in research paradigms away from the study of outcomes of sexuality and gender identity and the child/adolescent in isolation toward outcomes of adjustment and the child/adolescent in contexts that affect adjustment. Along with further discussions of the best treatment interventions, it is relevant to attempt to contribute to societal attitudes that enable children and adolescents with gender variance to express themselves and successfully complete the developmental tasks common to all, independent of gender.

\section{Disclosure}

The authors report no conflicts of interest in this work.

\section{References}

1. American Psychiatric Association. Diagnostic and Statistical Manual of Mental Disorders. 5th ed. Washington, DC: American Psychiatric Press; 2013.

2. World Health Organization. The ICD-10 Classification of Mental and Behavioural Disorders: Clinical Descriptions and Diagnostic Guidelines. Geneva: World Health Organization; 1992.

3. Drescher J, Cohen-Kettenis PT, Reed GM. Gender incongruence of childhood in the ICD-11: controversies, proposal, and rationale. Lancet Psychiatry. 2016;3(3):297-304.

4. Arcelus J, Bouman WP, Van Den Noortgate W, Claes L, Witcomb G, Fernandez-Aranda F. Systematic review and meta-analysis of prevalence studies in transsexualism. Eur Psychiatry. 2015;30(6):807-815.

5. Zucker KJ. Epidemiology of gender dysphoria and transgender identity. Sex Health. 2017;14(5):404-411.

6. Kuyper L, Wijsen C. Gender identities and gender dysphoria in the Netherlands. Arch Sex Behav. 2014;43(2):377-385.

7. Crissman HP, Berger MB, Graham LF, Dalton VK. Transgender demographics: a household probability sample of US adults, 2014. Am J Public Health. 2017;107(2):213-215.

8. Wood H, Sasaki S, Bradley SJ, et al. Patterns of referral to a gender identity service for children and adolescents (1976-2011): age, sex ratio, and sexual orientation. J Sex Marital Ther. 2013;39(1):1-6.

9. Aitken M, Steensma TD, Blanchard R, et al. Evidence for an altered sex ratio in clinic-referred adolescents with gender dysphoria. $J$ Sex Med. 2015;12(3):756-763.

10. Connolly MD, Zervos MJ, Barone CJ, Johnson CC, Joseph CL. The mental health of transgender youth: advances in understanding. JAdolesc Health. 2016;59(5):489-495. 
11. Sumia M, Lindberg N, Tyolajarvi M, Kaltiala-Heino R. Current and recalled childhood gender identity in community youth in comparison to referred adolescents seeking sex reassignment. J Adolesc. 2017;56:34-39.

12. Kroger J. Identity Development: Adolescence Through Adulthood. 2nd ed. Thousand Oaks, CA: Sage Publications; 2007.

13. Kroger J, Martinussen M, Marcia JE. Identity status change during adolescence and young adulthood: a meta-analysis. $J$ Adolesc. 2010;33(5):683-698.

14. Martin CL, Ruble DN. Patterns of gender development. Annu Rev Psychol. 2010;61:353-381.

15. Gray SAO, Carter AS, Levitt H. A critical review of assumptions about gender variant children in psychological research. J Gay Lesbian Ment Health. 2012;16(1):4-30.

16. Wharton A. The Sociology of Gender-An Introduction to Theory and Research. 2nd ed. Chichester: Wiley-Blackwell; 2012.

17. Alanko K, Santtila P, Harlaar N, et al. Common genetic effects of gender atypical behavior in childhood and sexual orientation in adulthood: a study of Finnish twins. Arch Sex Behav. 2010;39(1):81-92.

18. McCarthy MM, Auger AP, Bale TL, et al. The epigenetics of sex differences in the brain. J Neurosci. 2009;29(41):12815-12823.

19. Meyer-Bahlburg HF. Introduction: gender dysphoria and gender change in persons with intersexuality. Arch Sex Behav. 2005;34(4):371-373.

20. Knickmeyer R, Wang J, Zhu H, et al. Impact of sex and gonadal steroids on neonatal brain structure. Cereb Cortex. 2014;24:2721-2731.

21. Marrocco J, McEven BS. Sex in the brain: hormones and sex differences. Dialogues Clin Neurosci. 2016;18(4):373-338.

22. Ratnu V, Emami MR, Bredy TV. Genetic and epigenetic factors underlying sex differences in the regulation of gene expression in the brain. J Neurosci Res. 2017, 95:301-310.

23. Fausto-Sterling A, Crews D, Sung J, Garcia-Coll C, Seifer R. Multimodal sex-related differences in infant and in infant-directed maternal behaviors during months three through twelve of development. Dev Psychol. 2015;51(10):1351-1366.

24. Drescher J. Controversies in gender diagnoses. LGBT Health. 2013;1(1):10-14.

25. Steensma TD, McGuire JK, Kreukels BP, Beekman AJ, Cohen-Kettenis PT. Factors associated with desistence and persistence of childhood gender dysphoria: a quantitative follow-up study. $\mathrm{J}$ Am Acad Child Adolesc Psychiatry. 2013;52(6):582-590.

26. Steensma TD, Biemond R, de Boer F, Cohen-Kettenis PT. Desisting and persisting gender dysphoria after childhood: a qualitative followup study. Clin Child Psychol Psychiatry. 2011;16(4):499-516.

27. Steensma TD, Cohen-Kettenis PT. More than two developmental pathways in children with gender dysphoria? JAm Acad Child Adolesc Psychiatry. 2015;54(2):147-148.

28. Ristori J, Steensma TD. Gender dysphoria in childhood. Int Rev Psychiatry. 2016;28(1):13-20.

29. Singh D. A Follow-up Study of Boys with Gender Identity Disorder [Academic dissertation]. University of Toronto; 2012. Available from: https://tspace.library.utoronto.ca/bitstream/1807/34926/1/ Singh_Devita_201211_PhD_Thesis.pdf. Accessed January 11, 2018.

30. Hembree WC, Cohen-Kettenis PT, Gooren L, et al. Endocrine treatment of gender-dysphoric/gender-incongruent persons: an endocrine society clinical practice guideline. J Clin Endocrinol Metab. 2017;102(11):3869-3903.

31. Coleman E, Bockting W, Botzer M, et al. Standards of care for the health of transsexual, transgender, and gender-nonconforming people, version 7. Int J Transgend. 2011;13(4):165-232.

32. de Vries AL, Cohen-Kettenis PT. Clinical management of gender dysphoria in children and adolescents: the Dutch approach. $J$ Homosex. 2012;59(3):301-320.

33. Korte A, Lehmkuhl U, Goecker D, Beier KM, Krude H, GrutersKieslich A. Gender identity disorders in childhood and adolescence: currently debated concepts and treatment strategies. Dtsch Arztebl Int. 2008;105(48):834-841.
34. Viner R, Brain C, Carmichael P, Di Ceglie D. Sex on the brain: dilemmas in the endocrine management of children and adolescents with gender identity disorder. Arch Dis Child. 2005;90(2):A78.

35. Costa R, Carmichael P, Colizzi M. To treat or not to treat: puberty suppression in childhood-onset gender dysphoria. Nat Rev Urol. 2016;13(8):456-462.

36. Vrouenraets LJ, Fredriks AM, Hannema SE, Cohen-Kettenis PT, de Vries MC. Early Medical treatment of children and adolescents with gender dysphoria: an empirical ethical study. J Adolesc Health. 2015;57(4):367-373.

37. Shumer DE, Spack NP. Paediatrics: transgender medicine-long-term outcomes from 'the Dutch model'. Nat Rev Urol. 2015;12(1):12-13.

38. Spack NP, Edwards-Leeper L, Feldman HA, et al. Children and adolescents with gender identity disorder referred to a pediatric medical center. Pediatrics. 2012;129(3):418-425.

39. Kaltiala-Heino R, Sumia M, Tyolajarvi M, Lindberg N. Two years of gender identity service for minors: overrepresentation of natal girls with severe problems in adolescent development. Child Adolesc Psychiatry Ment Health. 2015;9:9.

40. Zucker KJ, Bradley SJ, Owen-Andersen A, Singh D. Puberty-blocking hormonal therapyfor adolescents with gender identity disorder: a descriptive clinical study. J Gay Lesbian Ment Health. 2011;15:58-82.

41. de Vries AL, Doreleijers TA, Steensma TD, Cohen-Kettenis PT. Psychiatric comorbidity in gender dysphoric adolescents. J Child Psychol Psychiatry. 2011;52(11):1195-1202.

42. Chen M, Fuqua J, Eugster EA. Characteristics of referrals for gender dysphoria over a 13-year period. J Adolesc Health. 2016;58(3): 369-371.

43. Meyenburg B. Gender dysphoria in adolescents: difficulties in treatment. Prax Kinderpsychol Kinderpsychiatr. 2014;63(6):510-522.

44. Khatchadourian K, Amed S, Metzger DL. Clinical management of youth with gender dysphoria in Vancouver. J Pediatr. 2014;164(4): 906-911.

45. Olson J, Schrager SM, Belzer M, Simons LK, Clark LF. Baseline physiologic and psychosocial characteristics of transgender youth seeking care for gender dysphoria. J Adolesc Health. 2015;57(4):374-380.

46. Holt V, Skagerberg E, Dunsford M. Young people with features of gender dysphoria: demographics and associated difficulties. Clin Child Psychol Psychiatry. 2016;21(1):108-118.

47. Steensma TD, Zucker KJ, Kreukels BP, et al. Behavioral and emotional problems on the Teacher's Report Form: a cross-national, cross-clinic comparative analysis of gender dysphoric children and adolescents. $J$ Abnorm Child Psychol. 2014;42(4):635-647.

48. de Vries AL, Steensma TD, Cohen-Kettenis PT, VanderLaan DP, Zucker KJ. Poor peer relations predict parent- and self-reported behavioral and emotional problems of adolescents with gender dysphoria: a cross-national, cross-clinic comparative analysis. Eur Child Adolesc Psychiatry. 2016;25(6):579-588.

49. Rodríguez MF, Mora PG, Sánchez EM, Gidseen G. Características de los menores de edad con disforia de género que acuden a la unidad de tratamiento de identidad de género. Rev Esp Salud Publica. 2017;91(1):e1-e9.

50. Zucker KJ, Bradley SJ, Owen-Anderson A, et al. Demographics, behavior problems, and psychosexual characteristics of adolescents with gender identity disorder or transvestic fetishism. J Sex Marital Ther. 2012;38:151-189.

51. Clark TC, Lucassen MF, Bullen P, et al. The health and well-being of transgender high school students: results from the New Zealand adolescent health survey (Youth'12). JAdolesc Health. 2014;55(1):93-99.

52. Diemer EW, Grant JD, Munn-Chernoff MA, Patterson DA, Duncan AE. Gender identity, sexual orientation, and eating-related pathology in a national sample of college students. $J$ Adolesc Health. 2015;57(2):144-149.

53. Van Der Miesen AI, Hurley H, De Vries AL. Gender dysphoria and autism spectrum disorder: a narrative review. Int Rev Psychiatry. 2016;28(1):70-80. 
54. Lai M, Lombardo MV, Baron-Cohen S. Autism. Lancet. 2014; 383(9920):896-910.

55. Strang JF, Kenworthy L, Dominska A, et al. Increased gender variance in autism spectrum disorders and attention deficit hyperactivity disorder. Arch Sex Behav. 2014;43(8):1525-1533.

56. van der Miesen AIR, deVries ALC, Steensma TD, Hartman CA. Autistic symptoms in children and adolescents with gender dysphoria. J Autism Dev Disord. Epub 2017 Nov 30.

57. Havighurst RJ. Developmental Tasks and Education. Chicago: University of Chicago Press; 1948.

58. Scheiffge-Krenke I, Gelhaar T. Does successful attainment of developmental tasks lead to happiness and success in later developmental tasks? A test of Havighurst's (1948) theses. J Adolesc. 2008;31: $33-52$.

59. Harvey RG, Stone Fish L. Queer youth in family therapy. Fam Process. 2015;54(3):396-417.

60. Gray SA, Sweeney KK, Randazzo R, Levitt HM. "Am I doing the right thing?" Pathways to parenting a gender variant child. Fam Process. 2016;55(1):123-138.

61. Mayer KH, Garofalo R, Makadon HJ. Promoting the successful development of sexual and gender minority youths. Am J Public Health. 2014;104(6):976-981.

62. Gonzalez KA, Rostosky SS, Odom RD, Riggle ED. The positive aspects of being the parent of an LGBTQ child. Fam Process. 2013;52(2):325-337.

63. Travers R, Bauer G, Pyne J, et al. Impacts of strong parental support for trans youth: a report prepared for children's aid society of Toronto and delisle youth services; 2012. Available from: http://transpulseproject. ca. Accessed October 4, 2017.

64. Wilson EC, Iverson E, Garofalo R, Belzer M. Parental support and condom use among transgender female youth. $J$ Assoc Nurses AIDS Care. 2012;23(4):306-317.

65. Le V, Arayasirikul S, Chen YH, Jin H, Wilson EC. Types of social support and parental acceptance among transfemale youth and their impact on mental health, sexual debut, history of sex work and condomless anal intercourse. $J$ Int AIDS Soc. 2016;19(2):20781.

66. Simons L, Schrager SM, Clark LF, Belzer M, Olson J. Parental support and mental health among transgender adolescents. J Adolesc Health. 2013;53(6):791-793.

67. Sumia M, Lindberg N, Työläjärvi M, Kaltiala-Heino R. Early pubertal timing is common among adolescent girl-to-boy sex reassignment applicants. Eur J Contracept Reprod Health Care. 2016;21(6):483-485.

68. Hall-Lande JA, Eisenberg ME, Christenson SL, Neumark-Sztainer D. Social isolation, psychological health, and protective factors in adolescence. Adolescence. 2007;42(166):265-286.

69. Laursen B, Hartl AC. Understanding loneliness during adolescence: developmental changes that increase the risk of perceived social isolation. JAdolesc. 2013;36(6):1261-1268.

70. Kornienko O, Santos CE, Martin CL, Granger KL. Peer influence on gender identity development in adolescence. Dev Psychol. 2016;52(10):1578-1592.

71. Shevlin M, Murphy S, Mallett J, Stringer M, Murphy J. Adolescent loneliness and psychiatric morbidity in Northern Ireland. Br J Clin Psychol. 2013;52(2):230-234.

72. Harris RA, Qualter P, Robinson SJ. Loneliness trajectories from middle childhood to pre-adolescence: impact on perceived health and sleep disturbance. J Adolesc. 2013;36(6):1295-1304.

73. Kaltiala-Heino R, Frojd S. Correlation between bullying and clinical depression in adolescent patients. Adolesc Health Med Ther. 2011;2:37-44.

74. Shiffman M, VanderLaan DP, Wood H, Lumley MM, Lollis SP, Zucker KJ. Behavioral and emotional problems as a function of peer relationships in adolescents with gender dysphoria: a comparison with clinical and nonclinical controls. Psychol Sex Orient Gender Divers. 2016;3(1):27-36
75. McGuire JK, Anderson CR, Toomey RB, Russell ST. School climate for transgender youth: a mixed method investigation of student experiences and school responses. JYouth Adolesc. 2010;39(10):1175-1188.

76. Bos H, Sandfort T. Gender nonconformity, sexual orientation, and Dutch adolescents' relationship with peers. Arch Sex Behav. 2015;44(5):1269-1279.

77. Toomey RB, Ryan C, Diaz RM, Card NA, Russell ST. Gendernonconforming lesbian, gay, bisexual, and transgender youth: school victimization and young adult psychosocial adjustment. Dev Psychol. 2010;46(6):1580-1589.

78. Baams L, Beek T, Hille H, Zevenbergen FC, Bos HM. Gender nonconformity, perceived stigmatization, and psychological well-being in Dutch sexual minority youth and young adults: a mediation analysis. Arch Sex Behav. 2013;42(5):765-773.

79. Reisner SL, Vetters R, Leclerc M, et al. Mental health of transgender youth in care at an adolescent urban community health center: a matched retrospective cohort study. J Adolesc Health. 2015;56(3):274-279.

80. Lawrence AA. Sexual orientation versus age of onset as bases for typologies (subtypes) for gender identity disorder in adolescents and adults. Arch Sex Behav. 2010;39(2):514-545.

81. Romeo KE, Kelley MA. Incorporating human sexuality content into a positive youth development framework: implications for community prevention. Child Youth Serv Rev. 2009;31(9):1001-1009.

82. Madkour AS, Farhat T, Halpern CT, Godeau E, Gabhainn SN. Early adolescent sexual initiation as a problem behavior: a comparative study of five nations. J Adolesc Health. 2010;47(4):389-398.

83. Savioja H, Helminen M, Frojd S, Marttunen M, Kaltiala-Heino R. Delinquency and sexual experiences across adolescence: does depression play a role? Eur J Contracept Reprod Health Care. 2017;22(4): 298-304.

84. Korchmaros JD, Ybarra ML, Mitchell KJ. Adolescent online romantic relationship initiation: differences by sexual and gender identification. J Adolesc. 2015;40:54-64.

85. Savioja H, Helminen M, Fröjd S, Marttunen M, Kaltiala-Heino R. Sexual experience and self-reported depression across adolescent years. Health Psychol Behav Med. 2015:3(1):337-347

86. Bungener SL, Steensma TD, Cohen-Kettenis PT, de Vries ALC. Sexual and romantic experiences of transgender youth before genderaffirmative treatment. Pediatrics. 2017;139(3):e20162283.

87. Robinson JP, Espelage DL. Peer victimization and sexual risk differences between lesbian, gay, bisexual, transgender, or questioning and nontransgender heterosexual youths in grades 7-12. Am J Public Health. 2013;103(10):1810-1819.

88. Veale J, Watson RJ, Adjei J, Saewyc E. Prevalence of pregnancy involvement among Canadian transgender youth and its relation to mental health, sexual health, and gender identity. Int $J$ Transgend. 2016;17(3-4):107-113.

89. Mitchell KJ, Ybarra ML, Korchmaros JD. Sexual harassment among adolescents of different sexual orientations and gender identities. Child Abuse Negl. 2014;38(2):280-295.

90. Dank M, Lachman P, Zweig JM, Yahner J. Dating violence experiences of lesbian, gay, bisexual, and transgender youth. $J$ Youth Adolesc. 2014;43(5):846-857.

91. Meyer IH. Prejudice, social stress, and mental health in lesbian, gay, and bisexual populations: conceptual issues and research evidence. Psychol Bull. 2003;129(5):674-697.

92. Poteat T, Scheim A, Xavier J, Reisner S, Baral S. Global epidemiology of HIV infection and related syndemics affecting transgender people. J Acquir Immune Defic Syndr. 2016;72(3):S210-S219.

93. Gowen LK, Winges-Yanez N. Lesbian, gay, bisexual, transgender, queer, and questioning youths' perspectives of inclusive school-based sexuality education. J Sex Res. 2014;51(7):788-800.

94. Kosciw JG, Palmer NA, Kull RM. Reflecting resiliency: openness about sexual orientation and/or gender identity and its relationship to well-being and educational outcomes for LGBT students. Am J Community Psychol. 2015;55(1-2):167-178. 
95. Poteat VP, Scheer JR, Mereish EH. Factors affecting academic achievement among sexual minority and gender-variant youth. Adv Child Dev Behav. 2014;47:261-300.

96. Theunissen MJ, de Man I, Verdonk P, Bosma H, Feron F. Are Barbie and Ken too cool for school? A case-control study on the relation between gender and dropout. Eur J Public Health. 2015;25(1):57-62.

97. Carvalho L. Childhood circumstances and the intergenerational transmission of socioeconomic status. Demography. 2012;49(3):913-938.

98. Jacob M, Cox SR. Examining transgender health through the international classification of functioning, disability, and health's (ICF) contextual factors. Qual Life Res. 2017;26(12):3177-3185.

99. Zucker KJ, Bradley SJ, Owen-Anderson A, Kibblewhite SJ, Cantor JM. Is gender identity disorder in adolescents coming out of the closet? J Sex Marital Ther. 2008;34(4):287-290.

100. Marchiano L. Outbreak: on transgender teens and psychic epidemics. Psychol Perspect. 2017;60:345-366.
101. Dhejne C, Lichtenstein P, Boman M, Johansson ALV, Långström $\mathrm{N}$, Landén $\mathrm{M}$ (2011). Long-term follow-up of transsexual persons undergoing sex reassignment surgery: cohort study in Sweden. PLoS One. 6(2): 16885.

102. de Vries AL, Steensma T, Doreleijers T, Cohen-Kettenis P. Puberty suppression in adolescents with gender identity disorder: a prospective follow-up study. J Sex Med. 2011;8:2276-2283.

103. Hidalgo MA, Ehrensaft D, Tishelman AC, et al. The gender affirmative model: what we know and what we aim to learn. Hum Dev. 2013;56(5):285-290.

104. Steensma TD, Cohen-Kettenis PT. Gender transitioning before puberty? Arch Sex Behav. 2011;40:649-650.

105. Zucker KJ. Persistence and desistence in children and adolescents with gender variance: a comparative-developmental perspective. J Am Acad Child Adolesc Psychiatry. 2016;55(10):S80.
Adolescent Health, Medicine and Therapeutics

\section{Publish your work in this journal}

Adolescent Health, Medicine and Therapeutics is an international, peer-reviewed, open access journal focusing on health, pathology, and treatment issues specific to the adolescent age group. All aspects of health maintenance, preventative measures and disease treatment interventions are addressed within the journal and practitioners from all disciplines are

\section{Dovepress}

invited to submit their work as well as healthcare researchers and patient support groups. This journal is included in PubMed. The manuscript management system is completely online and includes a very quick and fair peer-review system. Visit http://www.dovepress.com/testimonials. php to read real quotes from published authors. 